y su amor a la democracia, para ser presidente de la República Española en 1936.-J. Durand, "La idea de la honra en el Inca Garcilaso", pp. 194-213: El Inca tiene un concepto de la honra y la fama bastante innovador para la España de su época. Más que el linaje, toma en cuenta la virtud y las obras, y llega a insinuar que una acción heroica da honra aunque se realice en contra del rey. En esas ideas influyen sus lecturas humanísticas (León Hebreo, Guicciardini); pero además, "el tono afectivo con que las expresa muestra que su pensamiento está relacionado con su propia vida, personal y de americano".-M. Magdaleno, "Imágenes políticas de Rómulo Gallegos", pp. 234-259: "Aparte su excepcional rango como novelista, Rómulo Gallegos es actualmente el venezolano que ofrece un más jugoso y descollante pensamiento político". Desde Reinaldo Solar (1920) hasta Sobre la misma tierra (1943), pasando por Doña Bárbara (1929), su preocupación más honda es la situación política y social de Venezuela.-M. A. V.

\title{
KENTUCKY FOREIGN LANGUAGE QUARTERLY
}

Tomo $3\left(195^{6}\right)$.

F. D. Maurino, "El Viaje de Cervantes y la Comedia de Dante", pp. 7-12.El plan del Viaje del Parnaso y varios de sus pasajes son una ingeniosa parodia de la Divina comedia.

K. E. SHedD, "Thirty years of criticism of the works of Florencio Sánchez", pp. 29-39.-La abundante bibliografía crítica acerca de este dramaturgo (en la que se cuentan hasta ocho tesis universitarias norteamericanas) coincide en la apreciación de sus méritos y del sentido de su obra; pero hay cuatro puntos que se discuten: $a$ ) ¿pertenece a la literatura uruguaya o a la argentina?; $b$ ) ¿es realista o naturalista?; $c$ ) ¿qué autores europeos influyeron en él?; $d$ ) ¿es verdaderamente un gran dramaturgo?

J. D. Williams, "The savage in 16th-century Spanish prose fiction", pp. 4046.-En la novela del Siglo de Oro, especialmente en la caballeresca y en la pastoril, suelen aparecer "salvajes" velludos, feroces y de fea catadura. Los rasgos de esta figura convencional se fijaron en la Edad Media y el Renacimiento. [Sobre sus antecedentes y su relación con los verdaderos "salvajes" de América, véase ahora A. GERBr, La disputa del Nuevo Mundo, México, 1960, pp. 67-68].

J. M. Chavarri, "La vida y arte de José Santos Chocano, el poeta de América", pp. 67-75.-El autor trató personalmente a Chocano. Reconoce sus tristes fallas humanas, pero se muestra fascinado por el tono épico y "grandilocuente" de su poesía; Chocano, dice, es "la única luz que nos queda de la poesía épica americana".

W. A. Hunter, "The Alva manuscripts in Nahuatl in the Bancroft Library", pp. 76-81.-En 1641, el clérigo Bartolomé Alva, descendiente de los reyes de Tezcoco, tradujo al náhuatl El gran teatro del mundo y dos obras de Lope de Vega, El animal profeta y La madre de la mejor. El ms., cuyo rastro se había perdido, se halla en la Bancroft Library. Hunter se limita aquí (como en su tesis inédita de Tulane University, 1954) a estudiar la traducción de El gran teatro del mundo, cuya fecha (1641) debe tenerse en cuenta para fechar el auto original de Calderón, no publicado hasta 1655 . [Véase también C. Olmedilla en $\left.H M x, 7 \quad\left(1957-5^{8}\right), 237-23^{8}\right]$.

A. A. De Gennaro, "Américo Castro's conception of the Spaniards", pp. 104-111.-Según De Gennaro (profesor de Loyola University), Castro es un mero positivista, pues sostiene que el individualismo español se debe a influencia islámica y el sentido español de la honra a influencia judía, convirtiendo así 
al hombre en un objeto pasivo, fatalmente "moldeado por fuerzas sociailes externas".

K. Schwartz, "Russian literature in contemporary Ecuadorian fiction", pp. 141-145.-Los más importantes de los novelistas ecuatorianos de hoy son socialistas o comunistas, admiradores de la Rusia revolucionaria. Sin embargo, los novelistas rusos que más han influido en ellos no son los soviéticos como Ehrenburg o Sholójov, sino los pre-revolucionarios Dostoyevski, Andréiev y Gorki.

W. J. GRupp, "The influence of the premio Nadal on Spanish letters", pp. 162-168.-Después de ofrecer algunos datos estadísticos y un breve juicio sobre las novelas ganadoras de ese premio, de 1944 a 1955, concluye que su influencia ha sido valiosa.

H. HATZFELD, "The cultural value of studying historical linguistics", pp. 169183.-Artículo espléndidamente documentado, en que se hace ver, con abundantes ejemplos, la importancia que tiene para el lingüista el estudio del trasfondo histórico-cultural de las lenguas.

F. SEDwick, "Theses on Miguel de Unamuno at North American universities", pp. 192-196.-Es impresionante el número de estas tesis; once de ellas se presentaron en 1920-29; trece en 1930-39; diecisiete en 1940-49, y veintiséis de enero de 1950 a febrero de 1955 . [Véase ahora M. García Blanco en $C M d U$, $\left.8\left(195^{8}\right), 57-73\right]$.

H. C. WoOdBridge, "Spanish fiction in English translation: A bibliography for 1944-1955", pp. 197-205.-Lista (acompañada en algunos casos de breves comentarios) de sesenta novelas y cuentos traducidos al inglés en esos doce años. El autor más traducido es Ramón J. Sender (once títulos), seguido por Cervantes (nueve) y P. A. de Alarcón (siete).

Tomo 4 (1957).

J. R. Owre, “Arturo Mejía Nieto, story-teller from Honduras", pp. 15-30.Mejía Nieto, nacido en 19oo, ha estado fuera de su patria desde 1920; sus cuentos y novelas (en particular los primeros) evocan nostálgicamente el terruño y exponen los problemas sociales hondureños, que son, en palabras de uno de sus personajes, "las revoluciones, el alcoholismo, el analfabetismo, los hijos sin padre y la incapacidad para la acción". Pero Mejía Nieto no es un sociólogo, sino un artista que merecería ser mejor conocido, y uno de los cuentistas más interesantes de Centroamérica.

R. A. MacDonald, "Alfonso X on the authority and aims of kingship", pp. 83-9o.-Escrupulosa recolección de los pasajes de las Partidas, el Setenario, el Fuero real y el Espéculo que se refieren a la función del emperador y del rey en la sociedad humana, y a sus atributos y obligaciones.

W. J. Grupp, “José María Gironella, Spanish novelist”, pp. 129-135.-Presentación muy elogiosa del novelista y de sus tres primeras obras (Un hombre, La marea y Los cipreses creen en Dios). Gironella es, para Grupp, el mejor novelista que ha surgido en España después de 1936.

A. M. Pasquariello, "La muralla: the story of a play and a polemic", pp. 193-199.-Se refiere al éxito sensacional del drama de Joaquín Calvo Sotelo, a la acusación de plagio lanzada por una hija de Joaquín Dicenta (según la cual, La muralla es copia de La confesión de Dicenta), y a la polémica que se siguió. Pasquariello no cree que haya habido plagio, y recuerda que el tema aparece ya en $O$ locura o santidad de Echegaray. [Se puede añadir otro precedente que no veo mencionado: el cuento ¡Era un santo! del P. Coloma].

Tomo 5 (1958).


piltontli”, pp. 26-34--En el mismo ms. de la Bancroft Library en que están 
las piezas de Lope y Calderón traducidas al náhuatl por don Bartolomé Alva (cf. supra), hay un entremés, también en náhuatl, cuyos personajes son una vieja (ilamatzin), un muchacho (piltontli), un viejo, un alcalde, un escribano y dos sacristanes. El entremés tiene una trama muy simple, y termina en gritería y barahunda. Hunter cree que es obra original de Alva, y dice que el tema, "evidentemente mexicano" [?], recuerda los "juegos de escarnio de la Edad Media". [EI resumen que ofrece Hunter hace pensar en ciertos entremeses españoles de la época de Cervantes; no es difícil que se trate de una traducción más; en cuanto a los juegos de palabras que sólo tienen sentido en náhuatl, quizá se trate de simples adaptaciones de los que habría en el entremés original].

J. C. Davis, "Realism and humor in the Cid", pp. 66-73.-Comenta los pasajes del Poema del Cid en que hay pinturas realistas o rasgos humorísticos (como el episodio de Raquel e Vidas y el del león), y señala los recursos estilísticos de que se vale el poeta allí y en muchos otros lugares: naturalidad del diálogo, frecuencia de detalles descriptivos, precisión geográfica, exactitud de las cifras, caracterización física y psicológica de los personajes, etc.

C. W. Steele, "The Krausist educator as depicted by Galdós", pp. 136-142.Los ideales humanitarios y reformistas de León Roch (La familia de León Roch, 1878) y de Máximo Manso (El amigo Manso, 1882) reflejan con bastante fidelidad los de los krausistas españoles (con cuyo jefe espiritual, Giner de los Ríos, mantuvo Galdós estrecha amistad). Los dos personajes fracasan en su empeño, lo cual significa, seguramente, que el novelista no creía que España fuera terreno abonado para el programa pedagógico del krausismo. Roch y Manso "son dos de los personajes más simpáticos de Galdós, y a la vez dos de sus idealistas más patéticos”.

M. V. CAMpbell, "The cuentos of Oscar Castro Zagal", pp. 167-176.-Breve biografía de este poeta y cuentista chileno (1910-1947) y valoración de sus tres volúmenes de cuentos. Los mejores, en opinión de la profesora Campbell, son los del primer libro, Huellas en la tierra (1940). Los más tardíos están demasiado recargados de símiles y suelen ser melodramáticos o de mal gusto.-M. A. V.

\section{ANUARIO MUSICAL}

Tomo 1 (1946).

H. Spanke, "La teoría árabe sobre el origen de la lírica románica a la luz de las últimas investigaciones", pp. 5-18.-Rebate dicha teoría desde varios ángulos. "En lo concerniente a la forma musical general, la canción latina y la canción romance de la Edad Media forman un todo trabado, sin influencias extrañas". "La semejanza... entre el zéjel y el virelai aparece como producto externo y casual de dos líneas evolutivas independientes". Las coincidencias temáticas entre la lírica provenzal y la árabe pueden explicarse por cierta semejanza de las condiciones sociales y sobre todo por la igualdad básica del alma humana, que "en diferentes puntos del espacio y del tiempo lleva forzosamente a fenómenos paralelos". Por lo demás, la influencia árabe no es probable ni geográfica ni históricamente.

F. Pujol, "Clasificación de las canciones populares. Metodología", pp. 19-29.Propone una "clasificación de archivo" para la eventual formación de un Cancionero nacional español. Ve la necesidad de prescindir de la música y basarse fundamentalmente en los temas poéticos, como se ha venido haciendo; a la vez cree inevitable ciertas arbitrariedades, como la de atender en determinados casos al género poético o musical de la canción y no a su asunto. 